\title{
The Employee's Perception towards Work Performance in Arab Schools, Kuala Lumpur, Malaysia
}

Zainab Mohammed Alwan Al- Juboori, Harcharanjit Singh, Iwuchukwu Ekene, Shahiera Fazriena Mohd Foad, Ayu Andirah Sakka

To Link this Article: http://dx.doi.org/10.6007/IJARBSS/v11-i5/9689

DOI:10.6007/IJARBSS/v11-i5/9689

Received: 05 March 2021, Revised: 07 April 2021, Accepted: 30 April 2021

Published Online: 11 May 2021

In-Text Citation: (Juboori et al., 2021)

To Cite this Article: Juboori, Z. M. A. A.-, Singh, H., Ekene, I., Foad, S. F. M., \& Sakka, A. A. (2021). The Employee's Perception towards Work Performance in Arab Schools, Kuala Lumpur, Malaysia. International Journal of Academic Research in Business and Social Sciences, 11(5), 107-126.

Copyright: (c) 2021 The Author(s)

Published by Human Resource Management Academic Research Society (www.hrmars.com)

This article is published under the Creative Commons Attribution (CC BY 4.0) license. Anyone may reproduce, distribute, translate and create derivative works of this article (for both commercial and non-commercial purposes), subject to full attribution to the original publication and authors. The full terms of this license may be seen at: http://creativecommons.org/licences/by/4.0/legalcode

Vol. 11, No. 5, 2021, Pg. 107 - 126

Full Terms \& Conditions of access and use can be found at http://hrmars.com/index.php/pages/detail/publication-ethics 


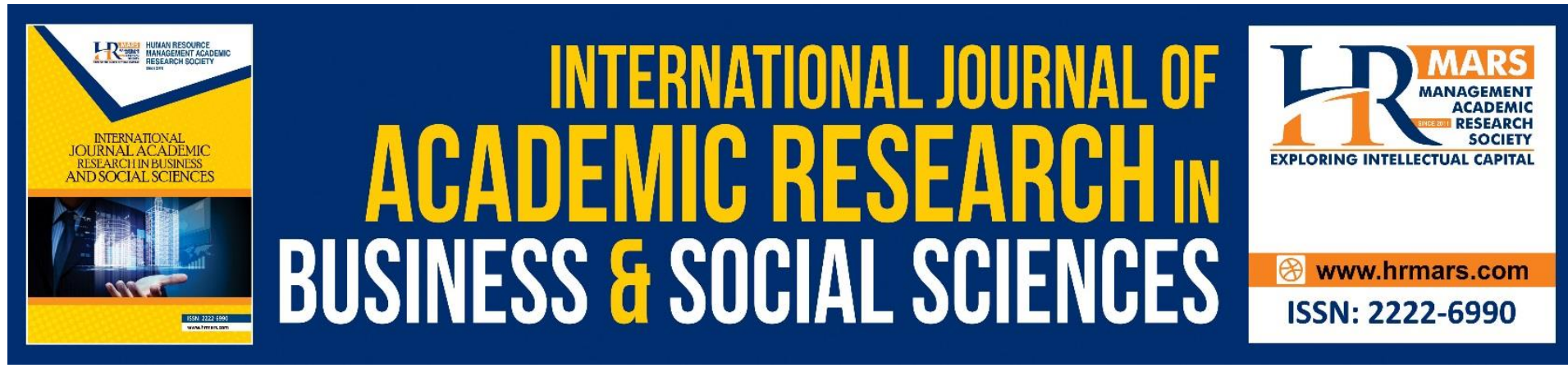

\title{
The Employee's Perception towards Work Performance in Arab Schools, Kuala Lumpur, Malaysia
}

\author{
Zainab Mohammed Alwan Al- Juboori, Dr. Harcharanjit \\ Singh, Iwuchukwu Ekene, Shahiera Fazriena Mohd Foad, Ayu \\ Andirah Sakka \\ Azman Hashim International Business School Universiti Teknologi Malaysia, Level 10, \\ Menara Razak, Jalan Semarak, 54100, Kuala Lumpur, Malaysia \\ Email: maazainab2@graduate.utm.my, harcharanjit@utm.my, ekene@graduate.utm.my \\ fazriena@graduate.utm.my, a.andirah@graduate.utm.my
}

\begin{abstract}
The present research aims to determine if there is a significant relationship between workplace diversity and work performance in Arab Schools in Kuala Lumpur (ASKL), Malaysia. Moreover, the demographic factors studied included age, gender, culture, and educational level. Moreover, two hundred and ten (225) respondents were examined using the data collected throughout the questionnaire through the Statistical Package for Special Science (SPSS) Software Version 24. Data were analyzed using descriptive statistics, factor analysis as well as regression analysis. In addition, the research presents an integrative model of demographic factors impact work performance. This research examines four demographic factors (age, gender, culture, and educational level) that affect the employee's work performance in (ASKL). The present research found a significant relationship between age, gender, culture, and work performance, while the research found no relationship between educational level and work performance. These findings emphasize the importance of workplace diversity toward work performance. Furthermore, this research fills the gaps between previous studies conducted in Arab schools by examining workplace diversity's impact on work performance. Furthermore, the present paper recommended future researchers add more diversity factors such as work experience or testing a mediation or moderation role such as motivation.
\end{abstract}

Keywords: Work Performance, Age, Gender, Culture, Educational Level

\section{Introduction}

Education plays a vital role in shaping tomorrow's leaders; education helps the nation or country improve by acquiring skills necessary for people to be productive members in society. The education system can be critical in shaping the future generation. The ministry of education's main objective is to help students discover their skills and talents to realize their best potential and develop their passion through learning (Türkkahraman, 2012). In addition, 
the middle east region faces the problem of performance declining in the educational sector for the past five (5) years due to many problems such as security, governmental, and diversity issues. The Arab education system is not preparing the students to compete globally and was due to the lack of good school performance, especially the primary levels where the children can grow their abilities and talents (Arar, 2010). Indeed, differences among Arab countries regarding their education system, such as urban and rural areas. However, almost all education systems in the Arab world suffer from performance shortcomings regarding governance and education (Hussain, 2014). Rockoff (2004) evaluated the Arab education system in Israel, where they stated that the ministry of education required the school's principals to enhance the process of decentralization throughout the system to support and increase the employee's performance. That accomplished by placing the authority for teacher and employee evaluation in the school principals' hands as a first step to see the trend of the employees and teacher performance in the coming years.

\section{Problem Statement}

work performance has a significant impact on the work productivity where leader/managers have the responsibility toward the workplace while they are responsible to set a policy that controls the difference among employee in terms of (age, gender, culture etc.) whereas this policies and strategies can eliminate the issue driven by diversity such as work performance, discrimination, and productivity (Hussain, 2014). Employees' performance evaluation can influence their behavior (Guillaume, Dawson, Otaye-Ebede, Woods and West, 2017). In addition, well-designed jobs positively impact both employee satisfaction and quality of their performance (Selvaraj, 2015). The employee's productivity has engaged to work performance and improving the organization's performance within a short period (Rockoff, 2004). An organization's performance is positively affected by the individual performance within the workplace, where the positive and negative outcomes are expected to contribute to its overall performance (Selvaraj, 2015). Despite its significant importance, Arab schools face a declining issue in employee performance (Hussain, 2014; Masoud, 2017; Rockoff, 2004). The present study highlighted the issues of performance declining in ASKL over five years and tried to study the most affected factor on employee's performance. Similarly, employee's work performance in seven (7) Arab Schools as following (SSMY, YS, IS, IMAS, Bs, SS, and LS) in Kuala Lumpur has declined significantly over five years. According to the data obtained from Human Resource Department in ASKL, the employee's appraisal performance has declined significantly due to unknown reasons. The work performance of the employees in ASKL have not been identified properly by the school's board since they have limited information regarding the factor that drove the performance down. Moreover, according to Masoud (2017) the performance of employees can be influenced by various factors and the most important factors are managing diversity within the workplace. They also stated that diversity can be a very serious issues if to managers are not ale to handle to invest it in the right way.

Table 1.1 displayed the employee's work performance for five years (2013-2017) in percentage. On average, the employee's work performance had declined from 97 percent in 2013 to 81 percent in 2017. 
Table 1.1: Employee's Work Performance in (ASKL)

\begin{tabular}{ccccccccc}
\hline Year & Saudi & Iraqi & IMAS & Yemeni & Syrian & Basserah & Libyan & Average \\
\hline 2013 & 99 & 99 & 99 & 97 & 92 & 99 & 97 & $\mathbf{9 7}$ \\
2014 & 94 & 88 & 97 & 94 & 91 & 98 & 93 & $\mathbf{9 3}$ \\
2015 & 92 & 80 & 95 & 91 & 90 & 95 & 91 & 90 \\
2016 & 89 & 72 & 90 & 90 & 88 & 94 & 90 & $\mathbf{8 7}$ \\
2017 & 80 & 70 & 85 & 89 & 82 & 77 & 88 & $\mathbf{8 1}$ \\
\hline
\end{tabular}

Source: Human Resource Department in (ASKL, 2018)

The declining issue of employee's performance was due to several factors, one of these factors is workplace diversity, which considers to be one of the most affected factors on work performance. Most of the studies that have been conducted in this field were to examine the factors that have a significant impact on the labor market as it contributes to rapid growth over the labor forces by shifting these factors as well as work performance (Kochan, Bezrukova, Ely, Jackson, Joshi, Jehn, \& Thomas, 2003). Nevertheless, there is a lack of studies conducted regarding work performance in ASKL. Akpakip (2017) stated that a future study needs to be conducted on the impact of diversity on work performance but on a broader scope and suggested future researchers to focus more on dimensions of diversity that affect the employee's performance. Work diversity defined in many ways, but it only leads to one main idea which is the difference among people such as age, gender, education, culture, experience, religion. These work diversity differences were considered the most affected factors in the work performed (Ogbo, Anthony \& Ukpere, 2014). The overall work performance is influenced by diversity established in the workplace for a long time. The individual's performance has highly influenced by diversity (Rockoff, 2004). Based on the past studies, the literatures supported the relationship between age, gender, culture, and educational level toward work performance are very limited and need to be explored more by future researcher to be able to have a boarder understanding regarding work performance issues and being able to generalize the results (Anyango \& Florah, 2019; Robbins, Judge, Millett \& Boyle, 2013).

Present study aims to fill the gap between several studies that have been done on the same research problem and the lack of studies done in Arab schools in Kuala Lumpur. Principals of (ASKL) should have sufficient awareness about factors influencing their employees' work performance by knowing the relationship between diverse demographical variables and work performance (Arar, 2010; Kundu \& Mor, 2017). This study could assist the principals and managers of (ASKL). Besides, this study considers to be the only study addressed (ASKL) regarding this issue, which could help the schools to increase their performance in the coming years. This research is hoped to provide useful findings with better understanding to the demographical factors impact on the work performance and how to control it. This study's findings may be necessary to any interested school, organization, or company that seek to understand the effect of (age, gender, cultural, and educational level,) has on their overall performance (Busolo, 2017). The present study is crucial in contributing to the usage of the underlying theories; Similarity Attraction Paradigm (SAP) and Social Identity (SI) theory. The research would provide the policymakers such as ministry of education and principals of Arab schools with valuable information about how to increase their employee's performance and what are the possible factors effecting it. The study's 
findings hoped to formulate guidelines for governing the work performed inside the schools in considering the individual characteristic by imposing strict regulations to govern the work performance. The motive to conduct this research due to the importance of ASKL in the region of Kuala Lumpur, especially where these schools are considered the top schools that provide Arabic curriculum and Islamic studies. Moreover, the declining of employee's performance in ASKL are very critical and need to be addressed by researchers urgently since the declining issues will affect the student's performance in the long term. The present research can provide a solution and few suggestions to be applied for better performance in the future especially when this study considered to be the only study done in (ASKL) regarding this problem which could help and assist the schools to increase their performance in the coming year. This research is hoped to provide useful findings that provide a better understanding of the demographic impact on the work performance and how we can control. It whereas the findings of this study may be important to any interested school, organizations or companies that seeks to understand the effect that (age, gender, educational level, culture diversity, etc) has on their overall performance (Busolo, 2017).

\section{Research Gap}

Akpakip (2017) who studied the impact of demographic factors (Age, Gender, Ethnically and educational level) in Bank Nigeria Ltd in Ota, Ogun State and suggested that future studies are needed on the same field but different sector and wider scope. Moreover, future researcher can focus on more dimensions of diversity that affect the performance of the employee. In some past empirical studies, most researchers narrowed their studies only focusing on a single aspect of workforce diversity e.g. multigenerational workforce or age diversity and employee productivity who studies age diversity and organizational performance (Bal, Kooij \& Rousseau, 2015; Ng \& Feldman, 2008; Ngao \& Mwangi, 2013) where Kunze, Boehm and Bruch (2013) studied gender diversity and employee productivity and last Wegge, Roth, Neubach, Schmidt, and Kanfer (2008) studied workforce ethnic diversity and group performance and suggested for more researches should be conducted in different diversity factors. Most of the studies that have been examine the dimensions of diversity and its impact on the employee performance are conducted in other countries than Malaysia. The past studies results cannot be generalized to all countries since each country have its own cultures and behaviours in the workplace such as finding the relationship between workforce diversity and organizational performance (Campion, Fink, Ruggeberg, Carr, Phillips \& Odman, 2011). Past studies were conducted in Ethiopia, Malaysia, Kenya, and Singapore respectively, where these researchers recommended a further study on the work diversity dimensions and its impact on the work performance to examine the relationship between selected dimensions and the work performance of the employees (Assefa, 2014; Maingi \& Makori, 2015; Weiliang, Mun, Fong, \& Yuan, 2011). Hence, this study conducted to fill the gap and it examined the relationship of four dimensions of diversity on the employee's performance in seven Arab schools located in Kuala Lumpur, Malaysia since no study have been conducted in ASKL to address the employee's performance issues which gave this study a novelty to contribute to the bod of knowledge in the management field. 


\section{Literature Review \\ Underpinning Theory}

This study employees two theories, namely, (a) social identity (SI) theory and (b) similarly attraction paradigm (SAP) theory as underpinning theory of the conceptual model to test empirically. (SI) theory supports the proposed framework by (Tajfel, 1978) and (SAP) theory was proposed by Thatcher (1999). These two (2) theories seek to determine the relationship between factors attributed to work performance. These two theories have been used in various studies to determine the individual character toward work performance and examine their relationships. (SI) and (SAP) theories have been used in many studies such as (Guillaume et al., 2017; Ogbo et al., 2014; Selvarajan, Slattery \& Stringer, 2015) to find the diverse characteristics among employees, understand what are these different, and to what extent it influences the performance. Moreover, to find a connection to between the demographical factors and work performance, they also stated that many demographic factors which impact work performances in diverse workplace and predict that these vast differences need to be adjusted from time to time (Akpakip, 2017). Rizwan, Khan, Nadeem, and Abbas (2016) found that a diverse workplace can negatively affect employees because of the lack of awareness among them of the beneficial aspect of diversity to the organization. Anyango and Florah (2019) conducted a study to examine the relationship between diversity and work performance. Their research's focus was based on four demographic factors that found a positive relationship toward work performance. They suggested future researchers conduct a similar study on different fields or cultures; they also recommended future researchers develop a general definition of workforce diversity and provide more benefits and implications of workforce diversity toward employees' performance. Many past researchers narrowed their studies to a single aspect of workforce diversity, e.g., multigenerational workforce or age diversity and employee productivity (Bal, Kooij \& Rousseau, 2015; Ng \& Feldman, 2008; Ngao \& Mwangi, 2013) age diversity and organizational performance. Kunze et al. (2013) studied gender diversity and employee productivity. Wegge et al. (2008) studied workforce ethnic diversity and group performance and suggested more research to conduct this study in different areas. Although various studies were conducted in Ethiopia, Malaysia, Kenya, and Singapore; past studies recommended a further investigation on the work diversity dimensions and their impact on the work performance (Assefa, 2014; Chew, Lee, Tan \& Tee, 2011; Karimi \& Busolo, 2019; Maingi \& Makori, 2015).

\section{Dependent Variable Work Performance}

Work performance is a dynamic assumed to be indicating the employee's behavior to accomplish a particular task in each organization's role (Gomez \& Bernet. 2019; Polyhart \& Hakel, 1998). Work Performance is vital in every organization, it considers the central part of every job assigned to deliver high productivity at work by utilizing the employee's skills and knowledge to reach the required potential (Combs, Liu, Hall \& Ketchen, 2006). Poor work performance is considered one of the biggest challenges that organizations face, leading to weak organizational structure, low work productivity, and lack of progress (Saxena, 2014). Various issues can be raised by having a low work performance within the organization, which lead to a need to establish effective strategies that help and support performance (Combs et al., 2006). Middle East regions, especially Egypt, Iraq, Yemen, and Syria, face a declining in performance in the educational sector for five years (from 2013 to 2017) due to many issues such as security, governmental, and diversity issues (Arar, 2010). There is a need for high work 
performance to have a higher outcome for a well-educated generation (Rockoff, 2004). Cho, Kim, and Barak (2017) found that a diverse workplace can create a negative feeling among employees because of the lack of awareness among them. Demographic factors that everyone has can lead one's performance to move upward or downward (Palakurthi \& Parks, 2000).

\section{Hypothesis Development}

This study develops a hypothesis and conceptual model considering the social identity theory and similarly attraction paradigm theory as underpinning theories.

\section{Gender Diversity and Work Performance}

Gender diversity means representing a company or organization of an equal proportion of men and women, where the equal treatment and acceptance of both male and female in an organization (Kunze, Boehm \& Bruch, 2013). Men and women are different in character and in performing the job as well. Moreover, it is well known that men are more physically active than females, which shows that males can perform better in the work that needs a physical ability. On the other hand, women are more verbal than men, which indicates that women can perform better in a work that required a speaker person such as teachers or lecturers (Cabo et al., 2019; Hassan \& Olufemi, 2014). However, some of these restrictions are removed where both men and women could do the work, and in that situation, we can compare their performance fairly (Pietinen, Hartman, Haapa, Rasanen, Haapakoski, Palmgren \& Huttunen,1988). In some Arab countries, women face difficulties due to the country's cultures where they men are preferred over women. In the Middle East, men can take over women position not because of his qualifications or performance but due to his gender (Hassan \& Olufemi, 2014). Past studies investigated the relationship between gender and work performance (Crawford \& Nonis, 1996; Shayo, Olfman, Iriberri \& Igbaria, 2007). However, researchers found that gender does not have an influence or impact on work performance.

Dowd and Benggtson (1978) suggested that women are better at performing the job assigned than men. While others stated that the relationship between gender and work performance is based on a different dimension with not mentioning the nature of this relationship, whether it was negative or positive (Green, Jegadeesh \& Tang, 2009; Ogunleye \& Osekita, 2016). Based on the literature review, there is inconsistency in the relationship between gender and employee performance. More research is needed to determine the impact of gender and work performance (Selvaraj, 2015). Based on the discussion, the following hypothesis was established.

\section{$\mathbf{H}_{1}$ : There is a significant relationship between gender and work performance}

\section{Age Diversity and Work Performance}

Age diversity is the ability to accept different age types within a business environment (Kunze et al., 2013). Knowing that age difference could lead to high or low performance is critical, and there is no such role stated that young people are better than older. Yearta, Maitlis, and Briner (1995) stated that age affects work performance, but he did not state the relationship whether positive or negative. Yearta et al. (1995) argued that performance and age depending on the nature of the work, environment, and the individual demographical factors. Another study said that the relationship between age and employee's job performance would be an 
issue in the coming years (Robbins et al., 2013). The assumptions made was, people who are getting older face a declining in their skills, speed, and performance due to the lack of intellectual simulations which reduce productivity (Robbins et al., 2013). On the other hand, the findings of Robbins et al. (2013) also stated that employee's age and job performance face a negative relationship. Testing the relationship between age and work performance has been studied by several researchers. However, after all past studies, there was no clear conclusion on the relationship between age and work performance (Kenny, Groeller, McGinn \& Flouris, 2016). More research is needed to determine the impact of age and work performance (Busolo, 2017). Based on the discussion, the following hypothesis was established.

\section{$\mathbf{H}_{2}$ : There is a significant relationship between age and work performance}

\section{Culture Diversity and Work Performance}

Culture diversity refers to the differences in culture in the same country or workplace where everyone is practicing his/her own culture regardless their culture (Kroeber \& Kluckhohn, 1952). Culture plays a significant role in the organization's performance within the organization which impacts the performance within the organization (Rehman \& Waheed, 2012). However, researchers also indicated that employees work in the same workplace sharing the same values and norms. However, it will eventually impact achieving the organization's mission. Organizational culture is the first factor influencing employee's performance (Hutabarat, 2015). Employees are getting their effectiveness and motivation from the workplace environment, he also stated a positive relationship between culture and work performance (Abdullah, 2020). In addition, Omondi (2014) found a significant relationship between the culture and employee performance. Based on the discussion, there is inconsistency in the relationship between culture and employee's performance. More research is needed to determine the impact of culture and work performance (Omondi, 2014). Based on the discussion, the following hypothesis was established.

\section{$\mathbf{H}_{3}$ : There is a significant relationship between culture and work performance}

\section{Educational Level Diversity and Work Performance}

Educational level is the difference among people regarding their educational level. In contrast, others have a high educational qualification, and it also refers to the educational certificate acquired in exchange for some knowledge gained (Kunze et al., 2013). Educational knowledge gained by a person can positively or negatively impact work performance. Therefore, having a high position at work required educational qualification in many cases. In some situations, managers focus on performance more than educational level especially in their promotional strategies (Carpenter \& Sanders 2002). Educational level is also related to the individual's creativity and behavior when well-educated employee could behave better than a less educated one (Kuncel, Hezlett \& Ones, 2004; Schmidt, Hunter \& Outerbridge, 1986). According to Cohen and Bailey (2001), effective work performance could be due to educational diversity where employees can have different capabilities and talents. Some jobs can only be done by those who have educational qualifications regardless their experiences, such as medical doctor. There is a significant positive relationship between different educational levels and talents with the overall work performed (Carpenter \& Fredrickson, 2001; Cohen \& Bailey, 2001). Simultaneously, others stated a negative impact of educational 
level on work performance (Bezrukova, Thatcher \& Jehn, 2007). Based on the literature review, there is inconsistency in the relationship between educational level on work performance. More research is needed to determine the impact of educational level and work performance (Bhardwaj, 2014). Based on the discussion, the following hypothesis was established.

$\mathbf{H}_{4}$ : There is a significant relationship between educational level and work performance

\section{Research Framework}

According to Rizwan et al. (2016) found that a diverse workplace can negatively affect employee's performance due to lack of awareness among them. Anyango and Florah (2019) conducted a study to examine the relationship between diversity and work performance, their research focus on four demographical factors which found a positive relationship toward work performance. They suggested future researchers conduct a similar study on different fields or cultures; they also recommended future researchers develop a general definition of workforce diversity and provide more benefits and implications of workforce diversity toward employee's performance. Many past researchers narrowed their studies to a single aspect of workforce diversity, e.g., multigenerational workforce, age diversity, and employee productivity (Bal et al., 2015; Ng \& Feldman, 2008; Ngao \& Mwangi, 2013). However, Kunze et al. (2013) studied gender diversity and employee productivity, while Wegge et al. (2008) studied workforce ethnic diversity and group performance and suggested more research to conduct this study in different areas. Although various studies were conducted in Ethiopia, Malaysia, Kenya, and Singapore; past studies recommended a further investigation on the work diversity dimensions and their impact on work performance (Assefa, 2014; Chew et al., 2011; Karimi \& Busolo, 2019; Maingi \& Makori, 2015;). Based on the literature review and the gap of the study, which grounded on (SI) and (SAP) theories, the research proposed the theoretical model on the relationships between workplace diversity (gender, age, culture, and educational level) toward work performance as shown in Figure 1.

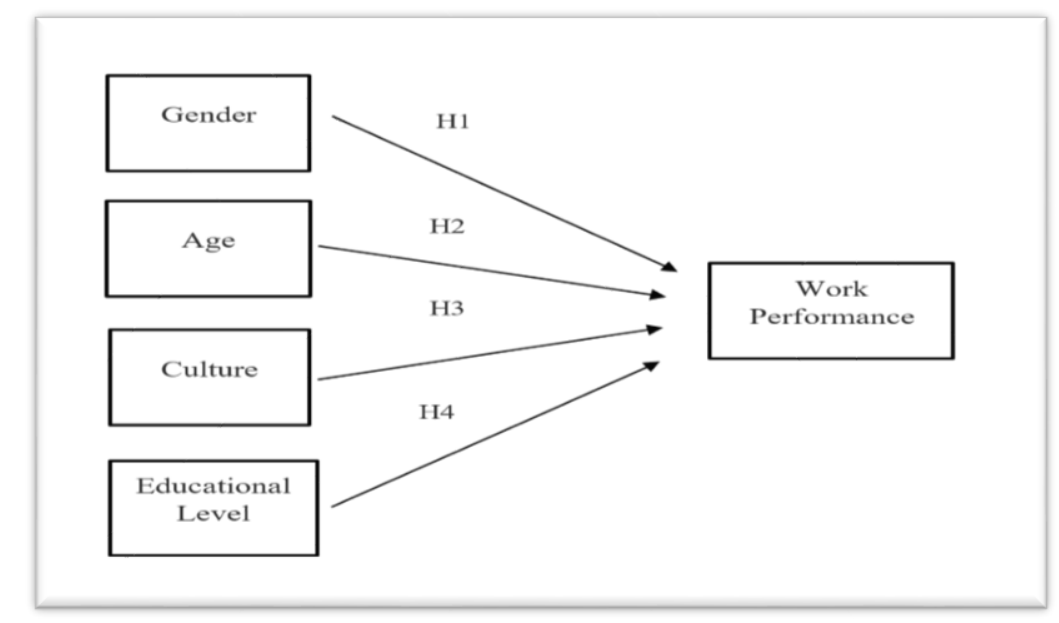

Figure 1: Theoretical Framework

\section{Research Methodology \\ Sampling and Data Collection}

This study employed a quantitative research design using a survey method. The target population was drawn from the human resource department of each school. The population 
selected for this study was the employees of Arab schools in a different location in Kuala Lumpur, Malaysia, namely (Saudi Schools, Iraqi school, Yemeni School, Syrian School, AlBaserah school, Libyan school, and IMAS school) which was 450 employees. The present research has used the probability sampling technique where every individual in the population is defined and has the same chance of being selected (Zikmund, Carr \& Griffin, 2013). Hence, the convenience sampling method was appropriate for the present research. The researcher calculated the sample size using the online population size calculator retrieved from the Creative Research System website by setting the confidence level at $95 \%$. Hence, the sample size of (207) was determined as the minimum number of respondents. Nevertheless, due to the fear of poor response rate, the number of questionnaires distributed was 300 . A self-administered questionnaire was distributed in the Schools during their official working hours and was collected personally by the researcher within six (6) months.

\section{Measures}

The measurements of age, gender, culture, and educational level were adopted from past study of Akpakip (2017). These measurements have been tested in multiple studies and approved for their high validity and reliability with the total number of five (5) items for age and four (4) for gender. In comparison, culture and educational level has been measured with seven (7) items each. Lastly, work performance measurements have been adopted from Chew et al. (2011) with six (6) items. All items were measured using five-point Likert-type scale. The questionnaire was distributed with a cover letter. The analysis unit in the present study was the school's employees because they were involved in the school's overall work running. Their views often represent the views of the entire school. Out of 300 questionnaires distributed, a total of 225 were received, giving a response rate of 75 percent. The selfdistribution method, follow-up, and reminder helped researcher to achieve a high respondent's rate. There is also no issue of non-response bias, and all questioned received was usable.

\section{Reliability and Validity}

A reliability test was conducted to examine the reliability of the items used. Cronbach Alpha was used to indicate how well the items measuring the variable and how they are correlated. Table 1 shows the reliability test and illustrating the items accepted and dropped. However, Sin (1994) stated that the reliability value falls between 0.50 and 0.60 is sufficient for exploratory research. Hence, this research accepts the items which scored more than 0.50 . However, four (4) items were deleted out of 26 items to achieve the higher Cronbach's coefficient alpha value.

Table 1: Reliability Results

\begin{tabular}{cccc}
\hline Variables & Items & $\begin{array}{c}\text { No of Items } \\
\text { deleted }\end{array}$ & $\begin{array}{c}\text { Cronbach's } \\
\text { Coefficient Alpha }\end{array}$ \\
\hline Gender & 4 & 1 & 0.660 \\
Age & 5 & None & 0.597 \\
Culture & 5 & 2 & 0.605 \\
Educational Level & 7 & None & 0.670 \\
Work Performance & 5 & 1 & 0.707 \\
\hline
\end{tabular}


Present research used factor analysis to check the validity using a Principal Component Analysis (PCA). Before performing the analysis, the suitability of the data was assessed. The Kaiser-Meyer-Olkin measure of sampling adequacy (KMO) was between 0.667 and 0.753 for the two constructs exceeding the threshold of 0.50 (See Tables $2 \& 3 \& 4 \& 5 \& 6$ ), and Bartlett's Test of Sphericity was statistically significant at $p<0.001$. Regarding factor analyses, the component analysis applied has resulted in single factor loading in each of the five (5) constructs; gender, age, culture, educational level, and work performance that explained 49.607 percent, 38.346 percent, 38.903 percent, 33.816 percent, and 49.170 percent of the variance, respectively. Only factors with a loading value of 0.50 and above were considered (Hair, Black, Babin, Andreson \& Tathman, 2006), and therefore no items were deleted. Thus, the results confirm the validity of the data.

Table 2: Factor Analysis - Gender

\begin{tabular}{llc}
\hline Items & Description & Loading \\
\hline G2 & $\begin{array}{l}\text { Opposite gender can perform well, and I enjoy working } \\
\text { with them }\end{array}$ & 0.673 \\
G3 & $\begin{array}{l}\text { Employees have not been discriminated by employer } \\
\text { during promotional opportunities based on gender }\end{array}$ & 0.724 \\
G4 $\quad$ Dissimilarity in gender leads to poor effectiveness \\
G5 $\quad$ Workforce of the same gender can easily form working \\
$\quad$ groups \\
Eigenvalues \\
Percentage of variance explained \\
KMO & 0.682 \\
Bartlett Test of Sphericity: & 0.737 \\
Approx & 1.984 \\
Df & 49.607 \\
Sig & 0.667 \\
\hline
\end{tabular}

Table 3: Factor Analysis - Age

\begin{tabular}{llc}
\hline Items & Description & Loading \\
\hline A1 & $\begin{array}{l}\text { My school leader includes all employees of different ages } \\
\text { in problem solving }\end{array}$ & 0.731 \\
A2 & Age difference affects group formation in the workplace & \\
A3 & Differences in age affects consensus building among & 0.534 \\
& employees. & 0.587 \\
A4 $\quad$ Age differences affects group effectiveness & 0.619 \\
A5 $\quad$ I have no problem working with people of different age & 0.635 \\
Eigenvalues & 1.917 \\
Percentage of variance explained & 38.346 \\
KMO & 0.705 \\
Bartlett Test of Sphericity: & 95.706 \\
Approx & 10 \\
Df & 0.000 \\
Sig &
\end{tabular}


Table 4: Factor Analysis - Culture

\begin{tabular}{llc}
\hline Items & Description & Loading \\
\hline C1 & My school develops its employee's human capability at all & 0.559 \\
& levels \\
C4 & My school continually invests in the development of its & 0.705 \\
& employee 's skills to remain competitive and meet on- \\
& going business needs \\
C5 & My school celebrates individual and team achievements \\
C6 & My school uses a full range of rewards and punishment to & 0.666 \\
& enforce high performance standards. & 0.577 \\
C7 $\quad$ My school treats me with dignity and respect & 0.560 \\
Eigenvalues & 1.945 \\
Percentage of variance explained & 38.903 \\
KOM & 0.689 \\
Bartlett Test of Sphericity: & 106.289 \\
Approx & 10 \\
Df & 0.000 \\
\hline Sig &
\end{tabular}

Table 5: Factor Analysis - Educational Level

\begin{tabular}{|c|c|c|}
\hline Items & Description & Loading \\
\hline EL1 & $\begin{array}{l}\text { My educational level and background affect my ability to } \\
\text { perform my core task responsibility }\end{array}$ & 0.658 \\
\hline EL2 & $\begin{array}{l}\text { The differences in educational background does not } \\
\text { encourage conflict among employees }\end{array}$ & 0.559 \\
\hline EL3 & $\begin{array}{l}\text { I experience lack of confidence due to my educational } \\
\text { background }\end{array}$ & 0.616 \\
\hline EL4 & $\begin{array}{l}\text { Working with colleagues with different educational } \\
\text { background affects our problem solving and decision- } \\
\text { making ability. }\end{array}$ & 0.583 \\
\hline EL5 & $\begin{array}{l}\text { I do my job perfectly when I am in a team of workmates } \\
\text { with different educational level }\end{array}$ & 0.622 \\
\hline EL6 & $\begin{array}{l}\text { Different educational background brings diverse } \\
\text { experience, and it enhances performance }\end{array}$ & 0.503 \\
\hline EL7 & $\begin{array}{l}\text { Having employees of the same educational levels and } \\
\text { background leads to high effectiveness }\end{array}$ & 0.512 \\
\hline \multicolumn{2}{|c|}{ Eigenvalues } & 2.367 \\
\hline \multicolumn{2}{|c|}{ Percentage of variance explained } & 33.816 \\
\hline \multicolumn{2}{|c|}{ KOM } & 0.774 \\
\hline \multicolumn{3}{|c|}{ Bartlett Test of Sphericity: } \\
\hline \multicolumn{2}{|c|}{ Approx } & 168.995 \\
\hline \multicolumn{2}{|c|}{ Df } & 21 \\
\hline \multicolumn{2}{|c|}{ Sig } & 0.000 \\
\hline
\end{tabular}


Table 6: Factor Analysis - Work Performance

\begin{tabular}{llc}
\hline Items & Description & Loading \\
\hline WP2 & $\begin{array}{l}\text { Good employee performance is important for the future } \\
\text { growth of my school }\end{array}$ & 0.628 \\
WP3 & I am given the chance to try my own method of doing the & 0.679 \\
& job & \\
WP4 & My performance level affects my salary level & 0.669 \\
WP5 & I enjoy my tasks and the division's work approach & 0.739 \\
WP6 $\quad$ By learning more skills, I can improve my task performance. & 0.678 \\
Eigenvalues & 2.309 \\
Percentage of variance explained & 46.170 \\
KOM & 0.753 \\
Bartlett Test of Sphericity: & 182.653 \\
Approx & 10 \\
Df & 0.000 \\
Sig &
\end{tabular}

\section{Research Findings}

\section{Profile of Respondents}

Table 7 presents the firms' demographic profiles. The demographic information consists of gender, age, and educational level.

Table 7: Descriptive Analysis - Respondents' Demographic Profile

\begin{tabular}{cccc}
\hline Particulars & Variable & Frequency & Percentage \\
\hline Gender & Male & 101 & 44.9 \\
\multirow{4}{*}{ Age } & Female & 124 & 55.1 \\
& Below 20 & 8 & 3.5 \\
& $21-30$ & 31 & 13.5 \\
\multirow{3}{*}{ Educational Level } & $31-40$ & 99 & 44.0 \\
& $41-45$ & 64 & 28.4 \\
& Bachelor's degree & 135 & 60.0 \\
& Master's degree & 58 & 25.8 \\
& PhD & 27 & 12.0 \\
& Others & 5 & 2.2 \\
\hline
\end{tabular}

In the present study, male and female were generally equal, where $55.1 \%$ were female, and $44.9 \%$ were male. Furthermore, the age distribution results revealed that there were two (2) majority age group between 31 - 40 years old (44.5\%) and 41 - 45 years old (28.4 $\%)$, followed by age 21 - 30 years old ( $13.5 \%)$, followed by $10.2 \%$ of the respondent's age of 46 and above. Minority of the respondents were with the age of below 20 years old accounted for only $3.5 \%$. Moreover, $60 \%$ of the respondents held a bachelor's degree, where $25.8 \%$ of the respondents were holding a master's degree, followed by $12 \%$ of the respondents holding a Ph.D. In contrast, only $2.2 \%$ of the respondents were holding other educational qualifications.

\section{Hypotheses Test}

$\mathbf{H}_{1}$ : There is a significant relationship between gender and work performance 
Based on the results shown in Table $8(B=0.943 ; \mathrm{t}$-value $=47.354, \mathrm{p}$-value $=0.000)$. P-value is lower than 0.05 . Therefore, $\mathbf{H}_{\mathbf{1}}$ is supported. The results obtained showed there is a positive and significant relationship between gender and work performance. Hence, it can be implied that work performance can vary between a male and female.

$\mathbf{H}_{2}$ : There is a significant relationship between age and work performance

Based on the results shown in Table $8(\theta=-0.015$; $\mathrm{t}$-value $=1.734, \mathrm{p}$-value $=0.045)$. P-value is lower than 0.05 . Therefore, $\mathbf{H}_{\mathbf{2}}$ is supported. There is a positive significant relationship between age and work performance. Thus, senior staff may not be as efficient and fast as the young generation. It could be concluded that employee's age is positive and significantly influences the work performed.

$\mathbf{H}_{3}$ : There is a significant relationship between culture and work performance

Based on the results shown in Table 8 ( $\beta=-015$; $\mathrm{t}$-value $=-0.757, \mathrm{p}$-value $=-0.045)$. P-value is lower than 0.05 . Therefore, $\mathbf{H}_{3}$ is supported. There is a significant relationship between culture and work performance. However, the relationship between culture and work performance was negative. However, high culture values could result in negative work performance.

$\mathbf{H}_{\mathbf{4}}$ : There is a significant relationship between educational level and work performance

Based on the results shown in Table $8(6=0.039 \mathrm{t}$-value $=1.935, \mathrm{p}$-value $=.054)$. P-value is higher than 0.05 . Therefore, $\mathbf{H}_{4}$ was not supported. There is no significant relationship between educational level and work performance. The results shows that educational level does not affect work performance; people with lower education background could also have a high work performance. Thus, having high educational level does not necessarily have level of work performance outcome. Table 8 illustrate the multiple regression model for the research variables.

Table 8: Multiple Regression Model - Coefficient

\begin{tabular}{ccccccc}
\hline & & \multicolumn{4}{c}{$\begin{array}{c}\text { Unstandardized } \\
\text { Coefficient }\end{array}$} & $\begin{array}{c}\text { Standardized } \\
\text { Coefficient }\end{array}$ \\
& Model & $\boldsymbol{B}$ & Std. Error & Beta & t & Sig. \\
\hline 1 & (Constant) & -.423 & .856 & & -.494 & .622 \\
Gender & 1.165 & .025 & .943 & 47.354 & .000 \\
& Age & .015 & .021 & .014 & 1.734 & .046 \\
& Culture & -.016 & .021 & -.015 & -.757 & -.045 \\
& Educational & .036 & .018 & .039 & $\mathbf{1 . 9 3 5}$ & .054 \\
& Level & & & & & \\
& & & &
\end{tabular}

Dependent Variable: WorkPerf

\section{Discussion}

The present research investigated the relationship between (gender, age, culture, and educational level) toward work performance in ASKL. The present research found a significant relationship between (gender, age, culture) and work performance. Gender and age affect 
work performance positively, while culture affects were negatively effect on work performance. However, the research could not find enough evidence to support the relationship between educational level and work performance. Thus, gender, age, and cultural diversity could influence work performance.

The positive relationship between gender diversity and work performance means that some employees like to work with the opposite gender to professionally carry out their job (Selvarajan et al., 2015). Moreover, the results also means that some jobs have been accomplished by certain gender better than the other, such as physical work where male can perform better than the female. This research gave the fact that the Arab school's management system support gender diversity and its implication. This research is similar to the previous studies (Chew et al., 2011; Naqvi et al., 2013)

In addition, age diversity has a significant positive impact on work performance. Nevertheless, young employees are performing better than old ones. However, the present research findings shows that young generation are highly important where youth can perform better than seniority. Moreover, with the advanced technology we are facing nowadays, schools need to go with the current flow and know all the possible and updated ways to do work smoothly. ASKL needs young employees who are better with the new work procedures supported by technologies. These findings align with past studies (Wegge et al., 2008).

The research found a negative relationship between cultural diversity and employees' work performance. The high cultural values among employees may negatively affect work performance. In contrast, low culture value among employees may positively affect employee work performance. Nevertheless, in this research, most of the employees in ASKL were from a similar culture and ethnicity, which may distort the results. The present research findings support that employees with high and strict cultural values would impact his/her work performance, it also will face several difficulties in adopting new cultures that goes with the work needs. Sometimes employees need to adjust their cultural values according to the work environment for better performance. Overall, every individual works with different culture and beliefs, when they join an organization that has an entirely different culture and beliefs from their own, they should be allowed to internalize themselves with the organization's values to know whether they can cope with organization or not.

The research could not find evidence to support the relationship between educational level and work performance. Hence, no relationship exists between educational level and work performance, which means that educational qualification does not impact performance, at the same time, other factors could enhance work performance more. Moreover, employees can improve their creativity and innovativeness regardless of their educational level. This will not be an obstacle for them to improve themselves and manage to solve problems and have decision-making abilities in the future. Employees who come into the organization bring different work experiences and expertise with them, which are more valuable than their educational background. Carmeli and Halevi (2009) argued that employees might have different knowledge and experience to make effective decisionmaking and improve the organization's work. However, educational diversity can bring about distress and argument when employees cannot build consensus; it can also reduce workplace cohesion. The educational level will not be an indicator of good work performance. Many successful people are considered to be the most achievable employees in the organization 
and do not own educational qualifications, however, they still can perform better than welleducated employees. Overall, the educational level does not impact work performance according to the present research findings, which means that employees in ASKL can perform well regardless of their educational background and their experience and abilities are much more important than their education. The results are similar to (Carpenter \& Sanders, 2002) who could not find enough evidence to support the relationship between educational level and work performance.

\section{Conclusion}

Employees differ in their personalities, and these differences influence how they react to the external and internal pressures that exist in any workplace. Most employees spend more than $50 \%$ of their daily time at work, and its environment greatly influences their performance. Employee's mental framework directly impacts their performance, which ultimately affects organization (Akpakip, 2017). The research found a positive and significant relationship between genders, age, and culture with work performance. The results did not find enough evidence to support the relationship between educational level with work performance. This research responds to the emerging trend of employee's perceptions by proposing a research framework to explain the employee's perception towards their work performance. The present theories of Social Identity (SI) and Similarity Attraction Paradigm (SAP) surrounding the influences of demographic factors on work performance which mostly explain that (gender, age, culture and educational level) predicts work performance. Policymakers could assist the Arab schools that wish to improve work performance by formulating policies and regulations that safeguard the employee's performance. Policymakers could impose a regulation that improve performance in ASKL. The research would help ministry of education and school's principals to monitor the employee's performance and ensure that the performance is enhanced over the years. The policymakers can continuously change their education policy that suits the time change and global needs.

This study was faced some limitations. First, the time frame; due to time constraints, the study was only limited to Arab Schools in Kuala Lumpur, Malaysia (ASKL). Secondly, the quality of the data is, the study made use of only 225 respondents. Thirdly, the accuracy of the data retrieved as a response from the population could not be ascertained because it is difficult to ascertain what employees gave as their response truly reflected their opinion of the issue in their work environment. Finally, the study only focused on limited areas of workforce diversity while there are various diversities components in the workplace. Future research should focus on the nature of the association between a single aspect of organizational performance and a single form of diversity to provide a comprehensive understanding of the relationship's nature. The researcher recommends future studies to be conduct the same framework but on a wider scope, it should include bigger population size (Akpakip, 2017). This study focused on a few workforce diversities. However similar study can be conducted using third variable (moderation or mediation) such as motivation.

\section{References}

Abdullah, A. (2020). Relationship the Work Culture and Training Programs Within Performance. International Journal of Progressive Sciences and Technologies, 20(1), 92101.

Akpakip, C. E. (2017). Effect of workforce diversity on employee performance in Nigerian 
banking industry (A study of Firstbank Nigeria Ltd., Ota Branch) (Doctoral dissertation, Covenant University, Ota, Nigeria.).

Anyango, O. M., \& Florah, O. M. (2019). Workforce Diversity and Performance of Kisumu Law Courts, Kenya. International Journal of Business and Social Science, 10(12).

Arar, K. (2010). Perception and use of teacher evaluation among elementary school principals in the Arab school system in Israel. Iyunin beminhal ubairgun hachinuch (Studies in educational administration and organization), 31, 325-349.

Assefa, A. W. (2014). Effect of Worforce Diversity Towards Employee Performance in Total Ethiopia S.C.

Bal, P. M., Kooij, D. T., \& Rousseau, D. M. (2015). Introduction to aging workers and the employee-employer relationship. In Aging workers and the employee-employer relationship (pp. 1-9). Springer, Cham.

Bezrukova, K., Thatcher, S. M., \& Jehn, K. A. (2007). Group heterogeneity and faultlines: Comparing alignment and dispersion theories of group composition. Conflict in organizational groups: New directions in theory and practice, 57-92.

Bhardwaj, B. R. (2014). Impact of education and training on performance of women entrepreneurs: A study in emerging market context. Journal of Entrepreneurship in Emerging Economies.

Busolo, E. (2017). The Impact of Workforce Diversity on Organizational Performance: A Case Study of Aar Group (Doctoral dissertation, United States International University-Africa).

Campion, M. A., Fink, A. A., Ruggeberg, B. J., Carr, L., Phillips, G. M., \& Odman, R. B. (2011). Doing competencies well: Best practices in competency modeling. Personnel psychology, 64(1), 225-262.

Carmeli, A., \& Halevi, M. Y. (2009). How top management team behavioral integration and behavioral complexity enable organizational ambidexterity: The moderating role of contextual ambidexterity. The Leadership Quarterly, 20(2), 207-218.

Carpenter, M. A., \& Fredrickson, J. W. (2001). Top management teams, global strategic posture, and the moderating role of uncertainty. Academy of Management journal, 44(3), 533-545.

Carpenter, M. A., \& Sanders, W. G. (2002). Top management team compensation: The missing link between CEO pay and firm performance?. Strategic management journal, 23(4), 367-375.

Chew, E. W., Lee, K. M., Tan, S. C., \& Tee, S. F. (2011). The effects of workforce diversity towards the employee performance in an organization (Doctoral dissertation, UTAR).

Cho, S., Kim, A., \& Mor Barak, M. E. (2017). Does diversity matter? Exploring workforce diversity, diversity management, and organizational performance in social enterprises. Asian Social Work and Policy Review, 11(3), 193-204.

Cohen, S. G., \& Bailey, D. E. (1997). What makes teams work: Group effectiveness research from the shop floor to the executive suite. Journal of management, 23(3), 239-290.

Combs, J., Liu, Y., Hall, A., \& Ketchen, D. (2006). How much do high-performance work practices matter? A meta-analysis of their effects on organizational performance. Personnel psychology, 59(3), 501-528.

Crawford, J. C., \& Nonis, S. (1996). The relationship between boundary spanners' job satisfaction and the management control system. Journal of Managerial Issues, 118131.

De Cabo, R. M., Terjesen, S., Escot, L., \& Gimeno, R. (2019). Do 'soft law'board gender quotas Work? Evidence from a natural experiment. European Management Journal, 37(5), 611- 
624.

Dowd, J. J., \& Bengtson, V. L. (1978). Aging in minority populations an examination of the double jeopardy hypothesis. Journal of gerontology, 33(3), 427-436.

Gomez, L. E., \& Bernet, P. (2019). Diversity improves performance and outcomes. Journal of the National Medical Association, 111(4), 383-392.

Green, C., Jegadeesh, N., \& Tang, Y. (2009). Gender and job performance: Evidence from Wall Street. Financial Analysts Journal, 65(6), 65-78.

Guillaume, Y. R., Dawson, J. F., Otaye-Ebede, L., Woods, S. A., \& West, M. A. (2017). Harnessing demographic differences in organizations: What moderates the effects of workplace diversity?. Journal of Organizational Behavior, 38(2), 276-303.

Hair, J. F., Black, W. C., Babin, B. J., Andreson, R. E., \& Tathman, R. L., (2006).Multivariate data analysis (Vol.) Upper Saddle River.

Hassan, B., \& Olufemi, O. (2014). Demographic variables and job performance: any link?. Acta Universitatis Danubius. CEconomica, 10(4).

Hussain, J. K. (2014). The Performnce of Arab Schools and the Government Rules. (Doctoral dissertation, Covenant University of Abu-Dhabi, UAE.).

Hutabarat, W. (2015). Investigation of teacher job-performance model: Organizational culture, work motivation and job-satisfaction. Jurnal Asian Social Science, 11(18), 295304.

Karimi, J., \& Busolo, E. (2019). Influence of Age Diversity on Organizational Performance: A Case Study of AAR Group.

Kenny, G. P., Groeller, H., McGinn, R., \& Flouris, A. D. (2016). Age, human performance, and physical employment standards. Applied physiology, nutrition, and metabolism, 41(6), S92-S107.

Kochan, T., Bezrukova, K., Ely, R., Jackson, S., Joshi, A., Jehn, K., ... \& Thomas, D. (2003). The effects of diversity on business performance: Report of the diversity research network. Human Resource Management: Published in Cooperation with the School of Business Administration, The University of Michigan and in alliance with the Society of Human Resources Management, 42(1), 3-21.

Kroeber, A. L., \& Kluckhohn, C. (1952). Culture: A critical review of concepts and definitions. Papers. Peabody Museum of Archaeology \& Ethnology, Harvard University.

Kuncel, N. R., Hezlett, S. A., \& Ones, D. S. (2004). Academic performance, career potential, creativity, and job performance: Can one construct predict them all?. Journal of personality and social psychology, 86(1), 148.

Kundu, S. C., \& Mor, A. (2017). Workforce diversity and organizational performance: a study of IT industry in India. Employee Relations.

Kunze, F., Boehm, S., \& Bruch, H. (2013). Age, resistance to change, and job performance. Journal of Managerial Psychology.

Maingi, J. W., \& Makori, M. (2015). Effect Of workforce diversity on employee performance in Kenya: A case of Kenya School of Government. Strategic Journal of Business \& Change Management, 2(2), 52-68.

Masoud, K, O. (2017). The Arab Education System and the Impact of Teachers Peformance on Students. Human Resource Management, 34(2), 53-7454.

Naqvi, S. R., Ishtiaq, M., Kanwal, N., Butt, M. U., \& Nawaz, S. (2013). Impact of gender diversity on team performance: The moderating role of organizational culture in telecom sector of Pakistan. Asian Journal of Social Sciences \& Humanities, 2(4), 228-235.

$\mathrm{Ng}, \mathrm{T}$. W., \& Feldman, D. C. (2008). The relationship of age to ten dimensions of job 
performance. Journal of applied psychology, 93(2), 392.

Ngao, E., \& Mwangi, C. (2013). Effects of managing gender of employees in enhancing organizational performance. A case study of Kenya ports authority. European Journal of Business and Management, 5(21), 50-62.

Ogbo, A. I., Anthony, K. A., \& Ukpere, W. I. (2014). The effect of workforce diversity on organizational performance of selected firms in Nigeria. Mediterranean Journal of Social Sciences, 5(10), 231-231.

Ogunleye, A. J., \& Osekita, D. A. (2016). Effect of job status, gender, and employees' achievement motivation behavior on work performance: a case study of selected local government employees in Ekiti State, Nigeria. European Scientific Journal, 12(26).

Omondi, D. O. (2014). The influence of organizational culture on employee job performance: A case study of Pacis insurance company limited (Doctoral dissertation, United States International University-Africa).

PIETINEN, P., HARTMAN, A. M., HAAPA, E., RÄSÄNEN, L., HAAPAKOSKI, J., PALMGREN, J., ... \& HUTTUNEN, J. K. (1988). Reproducibility and validity of dietary assessment instruments: I. A self-administered food use questionnaire with a portion size picture booklet. American journal of epidemiology, 128(3), 655-666.

Ployhart, R. E., \& Hakel, M. D. (1998). The substantive nature of performance variability: Predicting interindividual differences in intraindividual performance. Personnel Psychology, 51(4), 859-901.

Palakurthi, R. R., \& Parks, S. J. (2000). The effect of selected socio-demographic factors on lodging demand in the USA. International Journal of Contemporary Hospitality Management.

Rehman, R. R., \& Waheed, A. (2012). Work-family conflict and organizational commitment: Study of faculty members in Pakistani universities. Pakistan Journal of Social and Clinical Psychology, 10(1), 23-26.

Rizwan, M., Khan, M. N., Nadeem, B., \& Abbas, Q. (2016). The impact of workforce diversity towards employee performance: Evidence from banking sector of Pakistan. American Journal of Marketing Research, 2(2), 53-60.

Robbins, S., Judge, T. A., Millett, B., \& Boyle, M. (2013). Organisational behaviour: Pearson Higher Education AU.

Rockoff, J. E. (2004). The impact of individual teachers on student achievement: Evidence from panel data. American economic review, 94(2), 247-252.

Saxena, A. (2014). Workforce diversity: A key to improve productivity. Procedia Economics and Finance, $11,76-85$.

Schmidt, F. L., Hunter, J. E., \& Outerbridge, A. N. (1986). Impact of job experience and ability on job knowledge, work sample performance, and supervisory ratings of job performance. Journal of applied psychology, 71(3), 432.

Selvaraj, P. C. (2015). The effects of work Force diversity on employee performance in Singapore organisations. International Journal of Business Administration, 6(2), 17.

Selvarajan, T. T., Slattery, J., \& Stringer, D. Y. (2015). Relationship between gender and workrelated attitudes: a study of temporary agency employees. Journal of Business Research, 68(9), 1919-1927.

Shayo, C., Olfman, L., Iriberri, A., \& Igbaria, M. (2007). The virtual society: Its driving forces, arrangements, practices, and implications. In Psychology and the Internet (pp. 187219). Academic Press.

Sin, S. J. (1994). Late-time phase transition and the galactic halo as a Bose liquid. Physical 
Review D, 50(6), 3650.

Tajfel, H. E. (1978). Differentiation between social groups: Studies in the social psychology of intergroup relations. Academic Press.

Thatcher, A. R. (1999). The long-term pattern of adult mortality and the highest attained age. Journal of the Royal Statistical Society: Series A (Statistics in Society), 162(1), 5-43.

Türkkahraman, M. (2012). The role of education in the societal development. Journal of educational and instructional studies in the world, 2(4), 38-41.

Wegge, J., Roth, C., Neubach, B., Schmidt, K. H., \& Kanfer, R. (2008). Age and gender diversity as determinants of performance and health in a public organization: the role of task complexity and group size. Journal of Applied Psychology, 93(6), 1301.

Weiliang, E. C., Mun, L. S., Fong, T. S., \& Yuan, Y. P. (2011). The effects of workforce diversity towards the employee performance in an organization. Unpublished thesis, University Tunku Adbul Rahman.

Yearta, S. K., Maitlis, S., \& Briner, R. B. (1995). An exploratory study of goal setting in theory and practice: A motivational technique that works?. Journal of Occupational and Organizational Psychology, 68(3), 237-252.

Zikmund, W. G., Carr, J. C., \& Griffin, M. (2013). Business Research Methods (Book Only). Cengage Learning. 